DOI: https://doi.org/10.24127/ajpm.v9i2.2688

\title{
PENGEMBANGAN BAHAN AJAR BUKU DONGENG BERBASIS SAINSMATIKA UNTUK MENINGKATKAN PEMAHAMAN KONSEP
}

\author{
Imroatun Nurhidayah $^{1^{*}}$, Muhammad Nur Wangid ${ }^{2}$ \\ ${ }^{1,2}$ Magister Pendidikan Dasar, Universitas Negeri Yogyakarta, Yogyakarta, Indonesia \\ * Corresponding author. Jl. Colombo No.1 Karangmalang CT Depok, 55281, Sleman, Indonesia. \\ E-mail: $\quad$ schnee.wunder20@ gmail.com $^{1 *}$ \\ $\underline{m \text { nurwangid@uny.ac.id }}{ }^{2)}$
}

Received 16 February 2020; Received in revised form 08 June 2020; Accepted 29 June 2020

\begin{abstract}
Abstrak
Tujuan penelitian ini adalah untuk mendapatkan produk bahan ajar berupa buku dongeng berbasis sainsmatika yang layak dan efektif digunakan dalam pembelajaran di kelas. Metode penelitian yang digunakan adalah Research and Development yang meliputi 10 (sepuluh) langkah, diantaranya: studi pendahuluan dan pengumpulan data, perencanaan, pengembangan draf produk, uji coba lapangan awal, revisi produk hasil uji coba, uji coba lapangan, revisi produk hasil uji coba, uji pelaksanaan lapangan, penyempurnaan produk akhir, dan diseminasi \& implementasi. Setelah dilakukan validasi oleh ahli media, ahli materi dan ahli bahasa, dari skala penilaian 0-100, skor rerata hasil penilaian ahli media yaitu 87,75; ahli materi 80; dan ahli bahasa 86,6. Hasil penelitian menunjukkan bahwa produk buku dongeng berbasis sainsmatika yang dikembangkan terkategori "sangat baik" dan dinyatakan layak untuk digunakan dalam proses pembelajaran. Produk juga dinyatakan efektif dalam meningkatkan kemampuan pemahaman konsep setelah dilakukan uji pelaksanaan lapangan dengan membandingkan gain skor tes pemahaman konsep sains dan matematika siswa di kelas eksperimen dan kelas kontrol. Hasil analisis data menunjukkan gain skor tes pemahaman konsep siswa di kelas eksperimen I sebesar 0,75; kelas eksperimen II sebesar 0,72; dan kelas kontrol sebesar 0,52. Gain skor kelas eksperimen lebih tinggi dibandingkan dengan kelas kontrol. Kesimpulannya, buku dongeng berbasis sainsmatika layak dan efektif untuk meningkatkan pemahaman konsep sains dan matematika di kelas IV SD.
\end{abstract}

Kata kunci: dongeng; pemahaman konsep; sainsmatika.

\begin{abstract}
The aim of this study is to get a valid, practical, and effective Sainsmatika-based fairy tale book product used in classroom learning. This study is Reseach and Development that consist of 10 (ten) steps, research and information collectin, planning, develop primary form of product, preliminary field, main product revision, main field testing, operational product revision, operational field testing, final product revision and dissemination \& implementation. After being validated by media experts, material expert and linguists, from a rating scale 0-100, the mean score of media experts' ratings was 87,7;, material expert 80; and linguist 86,6. The results showed that the Sainsmatika-based fairy tale book product that was developed was categorized as "very good" and was declared suitable for use in the learning process.The product was also declared effective in increasing the ability to understand concepts after conducting field tests by comparing the gain scores of students' understanding of science and mathematics concept tests between experimental and control class. The results of the data analysis show the gain of the students' concept understanding test scores in the first experimental class was 0,75; second experimental class was 0,72; and the control calss was 0,52. The gain score of experimental class was higher than control class. So, Sainsmatika-based fairy tale books are fesible and effective for increasing understanding concept of science and mathematics in grade IV elementary school.
\end{abstract}

Keywords: conceptual understanding; fairy tales; sainsmatika. 


\section{PENDAHULUAN}

Sains dan matematika merupakan bidang yang tidak pernah lepas dalam perkembangan ilmu pengetahuan dan teknologi. Pemahaman siswa terhadap sains dan matematika sejak dini merupakan hal penting dalam menghadapi tantangan kehidupan di era modern abad 21. Dalam belajar sains dan matematika tentunya membutuhkan kemampuan berpikir logis dan sistematis. Kemampuan tersebut adalah hal pokok yang digunakan untuk menganalisis secara kritis permasalahan dalam konteks sains dan matematika untuk memecahkan masalah (problem solving). Kemampuan dasar berpikir yang penting dimiliki siswa adalah kemampuan pemahaman konsep. Jika siswa dapat memahami konsep maka seharusnya siswa dapat menyelesaikan persoalan sains dan matematika dengan baik yang ditandai dengan hasil belajar yang tinggi (Ayuningtyas dan Setiana: 2019).

Dalam kajian yang lebih sempit pada siswa kelas IV SD Negeri di Kecamatan Depok, melalui hasil wawancara dengan guru menunjukkan bahwa dari semua mata pelajaran yang diajarkan, sains dan matematika adalah mata pelajaran yang kurang diminati oleh siswa (67\%), sebelum bahasa Indonesia (50\%) dan IPS (17\%). Sedangkan hasil observasi pembelajaran di kelas IV pada materi gaya dan pecahan dihasilkan $75 \%$ siswa salah dalam menjawab pertanyaan kuis, hanya $20 \%$ siswa yang menjawab benar dan 5\% siswa tidak dapat menjawab. Siswa yang salah dalam menjawab dan siswa yang tidak bisa menjawab menunjukkan bahwa dirinya belum memahami konsep materi seutuhnya.

Kajian lebih lanjut melalui angket, $32 \%$ siswa menyatakan kurang menyukai mata pelajaran sains dan matematika dikarenakan siswa sukar dalam memahami materi yang dijelaskan oleh guru, $51 \%$ siswa kurang menyukai mata pelajaran sains dan matematika dikarenakan siswa sukar dalam memahami pembahasan materi yang ada pada buku, dan $17 \%$ siswa tidak suka sains dan matematika tanpa alasan.

Permasalahan yang dihadapi oleh siswa dan guru di SD Negeri di kecamatan Depok adalah kurangnya minat siswa pada mata pelajaran sains dan matematika yang menyebabkan rendahnya pemahaman konsep siswa. Untuk mengatasi permasalahan tersebut maka diperlukan bahan ajar yang menyenangkan. Bahan ajar yang menyenangkan, kreatif dan inovatif sangat dibutuhkan agar siswa tidak merasa bosan dalam belajar.

Pengembangan terhadap bahan bahan ajar pada mata pelajaran matematika sudah banyak dikaji oleh pakar dan peneliti seperti Putra dan Syarifudin (2019); Haryanti dan Saputro (2016); Argarini, Yazidah dan Kurniawati (2019); Munandar dan Rizki (2019); Setiawan dan Rizki (2018); Purwanto dan Rizki (2015); serta Rahmawati dan Vahlia (2017). Bahan ajar yang dikembangan bermacammacam mulai bahan ajar cetak hingga bahan ajar matematika berbasis komputer dan multimedia yang bertujuan sama yakni meningkatkan pembelajaran. Namun, dalam menentukan bahan ajar yang tepat perlu disesuaikan dengan kebutuhan siswa.

Hasil studi kebutuhan siswa menunjukkan $87 \%$ siswa menyatakan senang melakukan percobaan dan $85 \%$ siswa menyukai kegiatan membaca. Pada kegiatan membaca, tidak satu pun siswa menyukai buku pelajaran atau buku LKS, akan tetapi $37 \%$ siswa menyukai membaca buku dongeng, 
$31 \%$ siswa senang membaca komik, dan sisanya senang membaca ensiklopedia dan majalah. Jika dilihat dari temanya, sebanyak $42 \%$ siswa menyukai buku cerita bertema dongeng petualangan, $32 \%$ siswa menyukai cerita fantasi, dan sisanya menyukai cerita fabel, legenda dan nonfiksi. Dari data tersebut, buku bacaan yang disukai siswa kelas IV di SD Negeri se-kecamatan Depok adalah buku yang memiliki cerita dan terdapat ilustrasi tokoh yang lucu dan menarik. Dengan demikian bahan ajar yang dikembangkan adalah bahan ajar berupa buku dongeng berbasis sainsmatika.

Buku dongeng berbasis sainsmatika adalah buku ajar penunjang berupa cerita dongeng yang disusun dengan berdasarkan pada materi sains dan matematika secara terpadu. Buku dongeng berbasis sainsmatika memuat konsep-konsep materi sains dan matematika yang dikemas khusus secara menarik agar mudah dipahami oleh siswa. Cerita dongeng pada bahan ajar ini disusun sebagai pengantar untuk menyampaikan konsep-konsep materi sains dan matematika. Orde (2013) menyatakan bahwa dongeng memiliki dampak yang baik pada perkembangan kognitif anak, dongeng memberikan kesempatan kepada anak-anak untuk memahami konflik dalam cerita yang dapat meningkatkan pengalaman intelektual mereka. Johnson (2016) dalam studinya mendapati bahwa siswa yang membaca sastra anak seperti dongeng dapat membantu mereka untuk memahami dunia di sekitarnya.

Selain menyajikan cerita dongeng dan gambar ilustrasi yang menarik, bahan ajar ini juga menyajikan ringkasan materi yang memudahkan siswa untuk memahami konsep gaya dan pecahan, latihan soal pemahaman konsep, panduan aktivitas sains melalui praktikum mini dan lembar evaluasi diri dalam belajar. Menurut Andersone (2009) dongeng dapat membantu siswa mendapatkan pengetahuan matematika. Tidak hanya mengembangkan imajinasi siswa, dongeng juga dapat mengembangkan keterampilan siswa dalam menggunakan koneksi matematika, dongeng dapat dijadikan sarana belajar yang menyenangkan dalam meningkatkan pemahaman siswa terhadap materi matematika. Menggunakan buku bacaan anak-anak dan dongeng dalam pembelajaran matematika dapat membantu mengatasi peningkatan sikap matematika dan membantu siswa untuk lebih kreatif dan imajinatif yang tidak terbatas (Furner: 2017).

Pengembangan bahan ajar berupa dongeng lebih banyak dilakukan pada ranah bahasa seperti penelitian yang dilakukan oleh Febriani (2010), Saidah dan Damariswara (2019). Penelitian ini memberikan ide baru bahwa dongeng tidak terbatas pada bahasa. Penelitian ini didukung oleh Rokhmawati, Asih dan Pamungkas (2019) yang mengembangkan bahan ajar berupa dongeng dengan nama Rainbow Book pada materi bangun datar di kelas IV. Penelitian tersebut lebih fokus dalam mengoptimalkan hasil belajar matematika pada materi geometri. Selain itu, Purnama, Astuti dan Maryam (2019) yang mengkaji tentang buku dongeng elektronik sebagai media pembelajaran matematika berbasis budaya. Penelitian tersebut mengembangkan buku dongeng namun dalam bentuk buku elektronik dan lebih menekankan pada aspek budaya.

Dari kedua penelitian tersebut diperlukan pengembangan lebih lanjut bahan ajar berupa buku dongeng yang berbasis pada materi sains dan matematika secara terpadu di kelas IV SD khususnya materi gaya dan pecahan. 
Tujun penelitian ini yaitu untuk mendapatkan produk bahan ajar buku dongeng berbasis sainsmatika yang layak dan efektif digunakan dalam pembelajaran.

\section{METODE PENELITIAN}

Penelitian ini menggunakan jenis penelitian dan pengembangan atau research and development. Produk yang dikembangkan adalah bahan ajar berupa buku penunjang yaitu buku dongeng berbasis sainsmatika untuk siswa kelas IV SD. Subyek penelitian ini adalah siswa kelas IV SD negeri se-kecamatan Depok yang menjadi SD pilot dalam penerapan Kurikulum 2013, dengan total siswa 90 anak.

Prosedur pengembangan buku dongeng berbasis sainsmatika menggunakan model pengembangan oleh Borg \& Gall (1983) yang meliputi 10 (sepuluh) langkah, diantaranya: (1) studi pendahuluan dan pengumpulan data; (2) perencanaan; pengembangan draf produk; (4) uji coba lapangan awal; (5) revisi produk hasil uji coba; (6) uji coba lapangan; (7) revisi produk hasil uji coba; (8) uji pelaksanaan lapangan;

penyempurnaan produk akhir; dan (10) diseminasi dan implementasi.

Teknik pengumpulan data yang digunakan pada penelitian ini adalah melalui wawancara dan observasi untuk memperoleh data kebutuhan siswa terhadap bahan ajar, angket yang terdiri dari angket kebutuhan, angket respon siswa dan guru dan validasi ahli, tes untuk memperoleh data tentang pemahaman konsep siswa. Secara umum, semua teknik tersebut digunakan secara bersamaan dan saling melengkapi. Teknik analisis data dalam penelitian ini menggunakan teknik analisis deskriptif secara kualitatif dan kuantitatif. Teknik analisis deskriptif secara kualitatif digunakan untuk mendeskripsikan tahapan pengembangan produk buku dongeng berbasis sainsmatika. Analisis data secara kuantitatif digunakan untuk mendeskripsikan hasil kelayakan dan keefektifan buku dongeng berbasis sainsmatika dalam meningkatkan kemampuan pemahaman konsep siswa.

\section{HASIL DAN PEMBAHASAN}

Produk yang dikembangkan pada penelitian ini yaitu bahan ajar matematika dan IPA berupa buku dongeng berbasis sainsmatika. Prosedur pengembangan produk tersebut menggunakan model pengembangan Borg \& Gall (1983) yang terdiri dari beberapa tahap yang sudah dilaksanakan dalam mengembangkan bahan ajar tersebut. Tahapan-tahapan yang dimaksud beserta hasilnya sebagai berikut:

1. Studi pendahuluan dan pengumpulan data

Studi pendahuluan dilakukan untuk memperoleh informasi mendasar yang dapat digunakan sebagai latar belakang serta analisis kebutuhan. Studi pendahuluan dan pengumpulan data yang dilakukan meliputi studi pustaka, studi lapangan dan studi dokumen.

2. Perencanaan

Pada tahap ini peneliti membuat rencana pengembangan produk berdasarkan hasil studi pendahuluan. Perencanaan yang dilakukan salah satunya adalah menyusun jadwal pelaksanaan kegiatan penelitian dan pengembangan.

3. Pengembangan draf produk

Pengembangan draf produk dilakukan dengan membuat cerita dongeng, dilanjutkan dengan membuat ilustrasi gambar dan membuat layout draf buku dongeng. Pada tahap ini, draf produk yang dikembangkan dinilai atau 
divalidasi oleh ahli media, ahli materi, dan ahli bahasa. Sebelum dinilai, dinyatakan valid dan layak, produk buku dongeng berbasis sainsmatika dilakukan pembimbingan dan diberikan masukan-masukan oleh para ahli diantaranya ahli media, ahli materi dan ahli bahasa. Berikut adalah nilai hasil validasi dengan skor total 100 dan rentang skor mulai $0-20$ nilai $\mathrm{E}$ dan kategori "TB" (tidak baik); skor 21-40 nilai D kategori "KB" (kurang baik); skor 41-60 nilai C kategori "C" (cukup); skor 61-80 nilai B kategori "B" (baik); dan skor 81-100 nilai A kategori "SB" (sangat baik).

Tabel 1. Hasil validasi ahli media.

\begin{tabular}{clccc}
\hline No. & \multicolumn{1}{c}{ Indikator } & Skor & Nilai & Ket. \\
\hline 1. & $\begin{array}{l}\text { Cover (sampul) } \\
\text { Prelimenaries } \\
\text { (pendahuluan) }\end{array}$ & 83 & $\mathrm{~A}$ & $\mathrm{SB}$ \\
3. & $\begin{array}{l}\text { Text Matter } \\
\text { (bagian utama) }\end{array}$ & 90 & $\mathrm{~A}$ & $\mathrm{SB}$ \\
4. & $\begin{array}{l}\text { Postlimenaries } \\
\text { (penutup) } \\
\text { Rerata }\end{array}$ & 85 & $\mathrm{~A}$ & $\mathrm{SB}$ \\
& $\mathbf{8 7 , 7 5}$ & $\mathrm{A}$ & $\mathrm{SB}$ \\
\hline
\end{tabular}

Hasil validasi ahli media yang ditampilkan pada Tabel 1 menunjukkan bahwa secara keseluruhan aspek media buku dongeng berbasis sainsmatika memperoleh rerata skor 87,75 dengan nilai A dan termasuk dalam kategori "SB" (sangat baik).

Kemudian pada Tabel 2, hasil validasi oleh ahli materi menunjukkan bahwa produk buku dongeng berbasis sainsmatika memperoleh rerata skor secara keseluruhan 80 dengan nilai $\mathrm{B}$ dan terkategori "B" (baik).

Pada Tabel 3, hasil validasi oleh ahli bahasa menunjukkan bahwa skor rerata secara keseluruhan 86,6 dengan nilai A dan terkategori "SB".

Berdasarkan hasil validasi dan penilaian dari ahi media, ahli materi dan ahli bahasa, menunjukkan bahwa bahan ajar buku dongeng berbasis sainsmatika yang dikembangkan sudah baik dan dinyatakan layak untuk digunakan dalam proses pembelajaran di kelas.

Tabel 2. Hasil Validasi Ahli Materi Sains dan Matematika

\begin{tabular}{clccc}
\hline No & \multicolumn{1}{c}{ Indikator } & Skor & Nilai & Ket. \\
\hline 1. & Kelengkapan & 85 & $\mathrm{~A}$ & $\mathrm{SB}$ \\
2ateri & $\begin{array}{l}\text { Keakuratan Materi } \\
\text { Kegiatan yang } \\
\text { Mendukung Materi }\end{array}$ & 80 & $\mathrm{~B}$ & $\mathrm{~B}$ \\
3. & $\mathrm{B}$ & $\mathrm{B}$ \\
Kemutkhiran & 80 & $\mathrm{~B}$ & $\mathrm{~B}$ \\
$\begin{array}{l}\text { Materi } \\
\text { Upaya } \\
\text { meningkatkan } \\
\text { pemahaman } \\
\text { konsep }\end{array}$ & 80 & $\mathrm{~B}$ & $\mathrm{~B}$ \\
6engorganisasian \\
$\begin{array}{l}\text { Materi } \\
\text { Materi } \\
\text { mengembangkan } \\
\text { kemampuan } \\
\text { pemahaman } \\
\text { konsep }\end{array}$ & 80 & $\mathrm{~B}$ & $\mathrm{~B}$ \\
$\begin{array}{l}\text { Penggunaan } \\
\text { Notasi, Simbol, } \\
\text { dan Satuan } \\
\text { Jumlah }\end{array}$ & 80 & $\mathrm{~B}$ & $\mathrm{~B}$ \\
& & & & \\
\hline
\end{tabular}

Tabel 3. Hasil Validasi Ahli Bahasa

\begin{tabular}{clccc}
\hline No. & \multicolumn{1}{c}{ Indikator } & Skor & Nilai & Ket. \\
\hline $\begin{array}{l}\text { Menggunakan } \\
\text { bahasa Indonesia } \\
\text { yang baik dan } \\
\text { benar }\end{array}$ & 87 & $\mathrm{~A}$ & $\mathrm{SB}$ \\
\hline 2. & $\begin{array}{l}\text { Peristilahan dalam } \\
\text { PUEBI }\end{array}$ & 93 & $\mathrm{~A}$ & $\mathrm{SB}$ \\
\hline 3. & Kejelasan bahasa & 80 & $\mathrm{~B}$ & $\mathrm{~B}$ \\
\hline 4. & Kesesuaian bahasa & 83 & $\mathrm{~A}$ & $\mathrm{SB}$ \\
\hline 5. & $\begin{array}{l}\text { Kemudahan untuk } \\
\text { dibaca } \\
\text { Rerata }\end{array}$ & 90 & $\mathrm{~A}$ & $\mathrm{SB}$ \\
& $\mathbf{8 6 , 6}$ & $\mathrm{A}$ & $\mathrm{SB}$ \\
\hline
\end{tabular}

4. Uji coba lapangan awal

Setelah dilakukan penyusunan draf dan validasi produk oleh ahli, maka produk buku dongeng berbasis sainsmatika yang dikembangkan dapat digunakan dalam uji coba lapangan awal. Pada tahap ini, buku dongeng berbasis sainsmatika digunakan dalam 
pembelajaran kemudian siswa dan guru memberikan penilaian terhadap buku dongeng berbasis sainsmatika. Berikut adalah nilai hasil uji coba produk dengan skor total 100 dan rentang skor mulai 0-20 nilai E dan kategori "TB" (tidak baik); skor 21-40 nilai D kategori "KB" (kurang baik); skor 41-60 nilai C kategori " $\mathrm{C}$ " (cukup); skor 61-80 nilai B kategori "B" (baik); dan skor 81-100 nilai A kategori "SB" (sangat baik).

Tabel 4. Hasil Respon Guru Uji Coba Lapangan Awal

\begin{tabular}{clccc}
\hline No. & Indikator & Skor & Nilai & Ket. \\
\hline 1 & Kelayakan Isi & 80 & B & B \\
\hline 2 & Kebahasaan & 75 & B & B \\
\hline 3 & $\begin{array}{l}\text { Penyajian } \\
\text { materi }\end{array}$ & 77 & B & B \\
\hline 4 & Kegrafisan & 84 & A & SB \\
\hline & Rerata & $\mathbf{7 9}$ & B & B \\
\hline
\end{tabular}

Berdasarkan tabel 4, hasil penilaian guru melalui angket respon guru terhadap produk buku dongeng berbasis sainsmatika diperoleh skor rerata sebesar 79 dengan nilai $\mathrm{B}$ dan terkategori "B" (baik).

Tabel 5. Hasil Skor Respon Siswa Uji Coba Lapangan Awal

\begin{tabular}{clccc}
\hline No. & Indikator & Skor & Nilai & Ket. \\
\hline 1. & Kemenarikan & 92 & $\mathrm{~A}$ & $\mathrm{SB}$ \\
\hline 2. & Kejelasan & 85 & $\mathrm{~A}$ & $\mathrm{SB}$ \\
\hline 3. & Kemudahan & 90 & $\mathrm{~A}$ & $\mathrm{SB}$ \\
\hline 4. & $\begin{array}{l}\text { Memfasilitasi } \\
\text { pemahaman } \\
\text { materi }\end{array}$ & 90 & $\mathrm{~A}$ & $\mathrm{SB}$ \\
\hline & Rerata & $\mathbf{8 9 , 2}$ & $\mathrm{A}$ & $\mathrm{SB}$ \\
\hline
\end{tabular}

Selanjutnya pada tabel 5 , hasil penilaian siswa melalui angket respon siswa terhadap buku dongeng berbasis sainsmatika menunjukkan bahwa skor rerata sebesar 89,2 dengan nilai A dan terkategori "SB".

5. Revisi produk hasil uji coba

Produk buku dongeng berbasis sainsmatika yang diuji coba lapangan awal mendapat masukan dari guru dan siswa sehingga produk mendapat beberapa revisi sebagai berikut:

a. Ada beberapa bahasa yang kurang dipahami siswa sehingga perlu perbaikan.

b. Kurangnya tanda baca sehingga perlu ditambahkan.

6. Uji coba lapangan diperluas

Pada tahap uji coba lapangan diperluas, produk buku dongeng berbasis sainsmatika yang sudah direvisi sesuai saran guru kemudian diuji coba lagi kepada subjek yang berbeda dan lebih besar.

Tabel 6. Hasil Skor Respon Guru Uji Coba Lapangan Diperluas

\begin{tabular}{clccc}
\hline No. & Indikator & Skor & Nilai & Ket. \\
\hline $\mathbf{1}$ & Kelayakan Isi & 87 & A & SB \\
\hline $\mathbf{2}$ & Kebahasaan & 85 & A & SB \\
\hline $\mathbf{3}$ & $\begin{array}{l}\text { Penyajian } \\
\text { materi }\end{array}$ & 85 & A & SB \\
\hline $\mathbf{4}$ & Kegrafisan & 85 & A & SB \\
\hline & Rerata & $\mathbf{8 5 , 5}$ & A & SB \\
\hline
\end{tabular}

Pada Tabel 6, hasil penilaian guru melalui angket respon guru terhadap produk buku dongeng berbasis sainsmatika memperoleh skor rerata sebesar 85,5 dengan nilai $\mathrm{B}$ dan dalam kategori "B".

Tabel 7. Hasil Skor Respon Siswa Uji Coba Lapangan Diperluas

\begin{tabular}{clccc}
\hline No. & Indikator & Skor & Nilai & Ket. \\
\hline 1. & Kemenarikan & 92 & $\mathrm{~A}$ & $\mathrm{SB}$ \\
\hline 2. & Kejelasan & 92 & $\mathrm{~A}$ & $\mathrm{SB}$ \\
\hline 3. & Kemudahan & 90 & $\mathrm{~A}$ & $\mathrm{SB}$ \\
\hline $\begin{array}{l}\text { Memfasilitasi } \\
\text { pemahaman } \\
\text { materi }\end{array}$ & 85 & $\mathrm{~A}$ & $\mathrm{SB}$ \\
\hline & Rerata & $\mathbf{9 0}$ & $\mathbf{A}$ & SB \\
\hline
\end{tabular}

Pada Tabel 7, hasil penilaian siswa melalui angket respon siswa terhadap buku dongeng berbasis sainsmatika memperoleh skor rerata 90 dengan nilai A dengan kategori "B". 
7. Revisi produk hasil uji coba

Beberapa saran guru pada uji coba lapangan diperluas menghasilkan revisi produk buku dongeng berbasis sainsmatika. Saran yang diberikan sebagai berikut:
a. Cara lain dalam mengubah bentuk-bentuk pecahan matematika perlu ditambahkan.
b. Menyertakan peta konsep pada bagian awal sebelum bagian isi.

8. Uji pelaksanaan lapangan

Pada tahap ini, buku dongeng berbasis sainsmatika yang telah direvisi sesuai dengan saran dan masukan saat uji coba lapangan awal dan uji coba lapangan diperluas kemudian diuji keefektifannya dalam meningkatkan kemampuan pemahaman konsep melalui pembelajaran di kelas eksperimen I, kelas eksperimen II dan kelas kontrol.

Tabel 8. Ringkasan data nilai pretest dan posttest pemahaman konsep.

\begin{tabular}{clcccc}
\hline \multirow{2}{*}{ No } & \multirow{2}{*}{ Kelas } & \multicolumn{2}{c}{ Nilai Rata-Rata } & Gain & \multirow{2}{*}{ Ket. } \\
\cline { 3 - 4 } & & Pre-test & Post-test & Standard & \\
\hline 1. & Kontrol & 48 & 75 & 0,52 & Sedang \\
\hline 2. & Eksperimen I & 48,3 & 87 & 0,75 & Tinggi \\
\hline 3. & Eksperimen II & 46,7 & 85 & 0,72 & Tinggi \\
\hline
\end{tabular}

Berdasarkan hasil analisis terhadap kriteria tersebut, menunjukkan bahwa buku dongeng berbasis sainsmatika dinyatakan efektif untuk meningkatkan kemampuan pemahaman konsep. Terbukti dari hasil tes kemampuan pemahaman konsep pada Tabel 8 , nilai rata-rata dan gain pretest dan posttest pada kelas eksperimen lebih tinggi daripada kelas kontrol. Pada kelas eksperimen I nilai rata-rata posttest lebih tinggi daripada pretest yaitu $87>48,3$ dengan gain sebesar 0,75 termasuk dalam kriteria tinggi, pada kelas eksperimen II nilai rata-rata posttest juga lebih tinggi daripada pretest yaitu $85>46,7$ sehingga gain sebesar 0,72 dengan kriteria tinggi, sedangkan pada kelas kontrol nilai ratarata posttest memang lebih tinggi daripada kelas pretest yaitu $75>48$ namun gain standar hanya mencapai 0,52 dan termasuk kriteria sedang, sehingga peningkatan kemampuan pemahaman konsep pada kelas eksperimen lebih tinggi daripada kelas kontrol.
9. Penyempurnaan produk

Produk buku dongeng berbasis sainsmatika yang telah diuji cobakan di lapangan masih memiliki beberapa kekurangan seperti kesalahan penulisan. Maka dari itu, produk perlu disempurnakan sebelum akhirnya disebarluaskan. Hasil produk yang telah disempurnakan memuat beberapa komponen sebagai berikut:

a. Isi cerita dongeng dan ilustrasi gambar,

b. Peta konsep materi gaya dan pecahan,

c. Muatan materi sains dan matematika (gaya dan pecahan),

d. Ringkasan materi yang memudahkan siswa dalam memahami konsep.

e. Panduan eksperimen sains dan matematika materi gaya dan pecahan,

f. Kuis sebagai latihan soal pemahaman konsep, dan

g. Lembar evaluasi pemahaman konsep sains dan matematika. 
Sampel produk buku dongeng berbasis sainsmatika yang telah disempurnakan ditampilkan pada Gambar 1 dan 2.

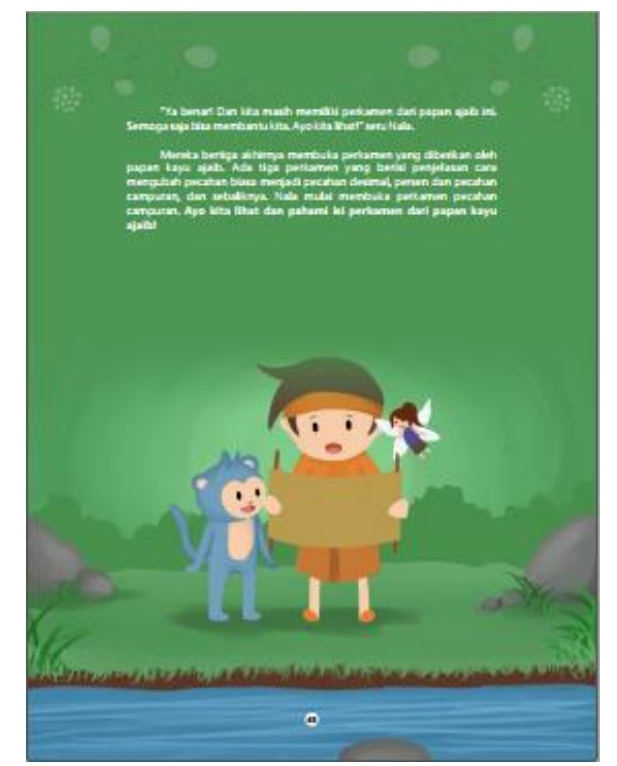

Gambar 1. Ilustrasi pada buku dongeng berbasis sainsmatika

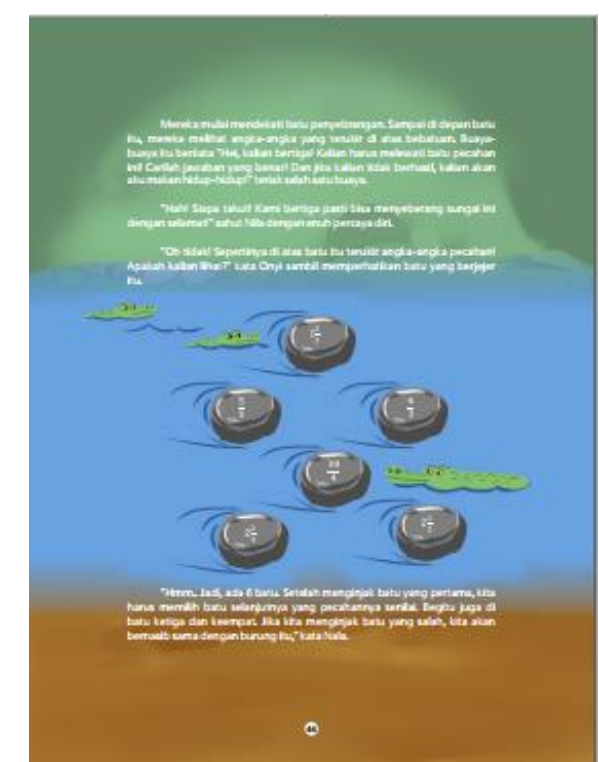

Gambar 2. Muatan materi matematika pada buku dongeng berbasis sainsmatika.

10. Diseminasi dan implementasi

Produk yang telah direvisi selanjutnya diimplementasikan dan disebarluaskan. Produk buku dongeng berbasis sainsmatika disebarluaskan di sekolah dasar di kecamatan Depok kabupaten Sleman agar dapat dimanfaatkan dengan baik oleh guru dan siswa.

Kriteria yang ditetapkan untuk efektivitas buku dongeng berbasis sainsmatika terhadap kemampuan pemahaman konsep adalah terdapat peningkatan yang signifikan antara nilai pretest dan posttest kemampuan pemahaman konsep, yaitu selisih nilai pretest dan posttest kemampuan pemahaman konsep pada kelas eksperimen lebih tinggi daripada selisih nilai pretest dan posttest kemampuan pemahaman konsep pada kelas kontrol.

Bahan ajar buku dongeng berbasis sainsmatika telah teruji kelayakannya karena telah memenuhi kriteria valid dan efektif, sehingga dapat dimanfaatkan dalam pembelajaran tematik di kelas IV SD. Bahan ajar ini dapat membantu siswa untuk memahami konsep materi pecahan serta materi gaya dan gerak melalui aktivitas membaca, mencoba dan mengerjakan latihan soal dengan cara yang menyenangkan melalui cerita dongeng. Bahan ajar buku dongeng berbasis sainsmatika juga dapat digunakan sebagai buku penunjang dan sebagai bahan bacaan yang dapat mengatasi kesulitan siswa dalam memahami konsep materi sains dan matematika secara terpadu.

Hal ini sejalan dengan penelitian yang dilakukan oleh Sari (2015), bahan ajar tematik yang berisi cerita bergambar dapat meningkatkan kemampuan pemahaman konsep pada pembelajaran tematik siswa SD. Kemudian penelitian oleh Ridwan (2016) yang merekomendasikan penggunaan sastra anak untuk bahan ajar sebagai sarana hiburan yang menyenangkan. Sehingga dalam 
pembelajaran di dalam kelas siswa tidak merasa bosan.

Penelitian ini memberikan dampak yang positif dalam perkembangan ilmu pengetahuan dan teknologi. Seperti pernyataan Orde (2013); Andersone (2009); Furner (2017); serta Purnama, Astuti dan Maryam (2019) dimana pengembangan bahan ajar berupa dongeng dapat menjadi sarana yang menyenangkan untuk memperoleh pemahaman sains dan matematika. Hasil penelitian ini membuktikan bahwa bahan ajar yang menyenangkan dapat memberikan efek yang positif terhadap proses pembelajaran. Hal ini sejalan dengan pernyataan Putra dan Syarifudin (2019); Haryanti dan Saputro (2016); Munandar dan Rizki (2019); Setiawan dan Rizki (2018); Purwanto dan Rizki (2015); Rahmawati dan Vahlia (2017); serta Rokhmawati, Asih dan Pamungkas (2019).

\section{KESIMPULAN DAN SARAN}

Penelitian ini mengembangkan produk bahan ajar berupa buku dongeng berbasis sainsmatika. Bahan ajar yang dihasilkan adalah buku dongeng berbasis sainsmatika yang valid dan efektif sehingga dapat dimanfaatkan dalam pembelajaran di kelas. Khususnya dapat membantu meningkatkan pemahaman konsep siswa terhadap materi pelajaran sains dan matematika. Bahan ajar yang disusun secara sistematis dan disesuaikan dengan kebutuhan siswa dapat memberikan manfaat dan yang paling penting adalah dapat mencapai tujuan pembelajaran. Bahan ajar untuk siswa sekolah dasar perlu disusun semenarik mungkin agar siswa tidak bosan, terlebih pada materi atau mata pelajaran yag tidak disukai oleh siswa.
Saran pemanfaatan produk yang dikembangkan adalah produk yang dikembangkan dapat dijadikan sebagai referensi dan bahan masukan bagi guru dalam pembelajaran di kelas, khususnya pada muatan materi matematika dan sains untuk meningkatkan kemampuan pemahaman konsep siswa. Selain itu, pengembangan buku dongeng berbasis sainsmatika ini hanya dilakukan pada materi pecahan, gaya dan gerak sehingga peneliti lain diharapkan dapat mengembangkan buku dongeng berbasis sainsmatika pada materi lainnya.

\section{DAFTAR PUSTAKA}

Andersone, R. (2009). Through FairyTales to Math in The Lessons. Acta Didactica Napocensia, 2 (2). Argarini, D. F., Yazidah, N. I. \& Kurniawati, A. (2019). Pengembangan Smart Book Materi Geometri untuk Siswa SMP Berbasis Konstruktivisme. Jurnal Pendidikan Matematika FKIP UM Metro, 8 (2): 344-353.

Ayuningtyas, A. D. \& Setiana D. S. (2019). Pengembangan Bahan Ajar Matematika Berbasis Etnomatematika Kraton Yogyakarta. AKSIOMA: Jurnal Program Studi Pendidikan Matematika, 8 (1), 11-19.

Febriani, M. (2010). Pengembangan Bahan Ajar Apresiasi Dongeng Banyumas Bagi Siswa SD Kelas Rendah. Jurnal Pendidikan Bahasa dan Sastra Indonesia FBS UNNES, 1 (1): 1-8.

Furner, J. M. (2017). Using Fairy Tales and Children's Literature in The Math Classroom: Helping All Students Become Einstein's in a STEM World. Journal of Advances in Education, 2 (2): 103 $-113$. 
Haryanti, F. \& Saputro, A. (2016). Pengembangan Modul Matematika Berbasis Discovery Learning Berbantu Flipbook Maker untuk Meningkatkan Pemahaman Konsep Pada Materi Segitiga. Jurnal Pendidikan Matematika, 1 (1): 147-161.

Johnson, L. V. The Positive Impacts of Fairy Tales for Children. Hohonu, 14: 77-81.

Munandar, A. \& Rizki, S. (2019). Pengembangan Bahan Ajar Matematika Berbasis Komputer Menggunakan Flipbook Maker Disertai Nilai Islam Pada Materi Peluang. AKSIOMA: Jurnal Program Studi Pendidikan Matematika, 8 (1), 262-269.

Orde, H. V. (2007). Children Need Fairy Tales Bruno Bettelheim's The Uses of Enchantment. Televizion Journal 26 /2013/E.

Purnama, E., Astuti, E. P., \& Maryam, I. (2019). Buku Dongeng Elektronik sebagai Media Pembelajaran Matematika Berbasis Budaya. PRISMA, Prosiding Seminar Nasional Matematika, 2, 323-329.

Purwanto, Y. \& Rizki, S. (2015). Pengembangan Bahan ajar Berbasis Kontekstual Pada Materi Himpunan Berbantu Video Pembelajaran. AKSIOMA: Jurnal Program Studi Pendidikan Matematika, 4(1), 67-77.

Putra, R. P. \& Syarifuddin, H. (2019). Pengembangan Bahan Ajar Penyajian Data Berbasis Pendidikan Karakter di Kelas IV Sekolah Dasar. Jurnal Basicedu: Journal of Elementary Education, 3 (2).

Rahmawati, Y. \& Vahlia, I. (2017). Pengembangan Bahan Ajar
Berbasis E-Learning Pada Matakuliah Evaluasi Pembelajaran untuk Meningkatkan Hasil Belajar Mahasiswa. AKSIOMA: Jurnal Program Studi Pendidikan Matematika, 6(2), 169-177.

Ridwan, M. (2016). Ajaran Moral dan Karakter dalam Fabel Kisah dari Negeri Dongeng Karya Mulasih Tary (Kajian Sastra Anak sebagai Bahan Ajar di Sekolah Dasar). Premiere Educndum, 6 (1): 95109.

Rokhmawati, A., Asih, I., \& Pamungkas, A.S. (2019). Pengembangan Bahan Ajar Rainbow Book Pada Materi Bangun Datar Kelas IV. Supremum Jurnal of Mathematics Education (SJME), 3 (2): 85-95.

Saidah, M. \& Damariswara, R. (2019). Pengembangan Bahan Ajar Materi Dongeng Berbasis Kearifan Lokal JawaTimur Bagi Siswa Kelas III SD. Premiere Educandum: Jurnal Pendidikan Dasar dan Pembelajaran, 9 (1): 73-81.

Sari, V. K. (2015). Pengembangan Bahan Ajar Berbasis Cerita Bergambar untuk Meningkatkan Pemahaman Konsep Pada Subtema 2 Lingkungan Sekitar Rumahku Kelas 1 SDN Genukwatu IV Ngoro Jombang. Undergraduate Thesis, Universitas Islam Negeri Maulana Malik Ibrahim.

Setiawan, E. \& Rizki, S. (2018). Pengembangan Bahan Ajar Barisan dan Deret Matematika Berbasis Multimedia Interaktif. AKSIOMA: Jurnal Program Studi Pendidikan Matematika, 7(3), 465-472. 